
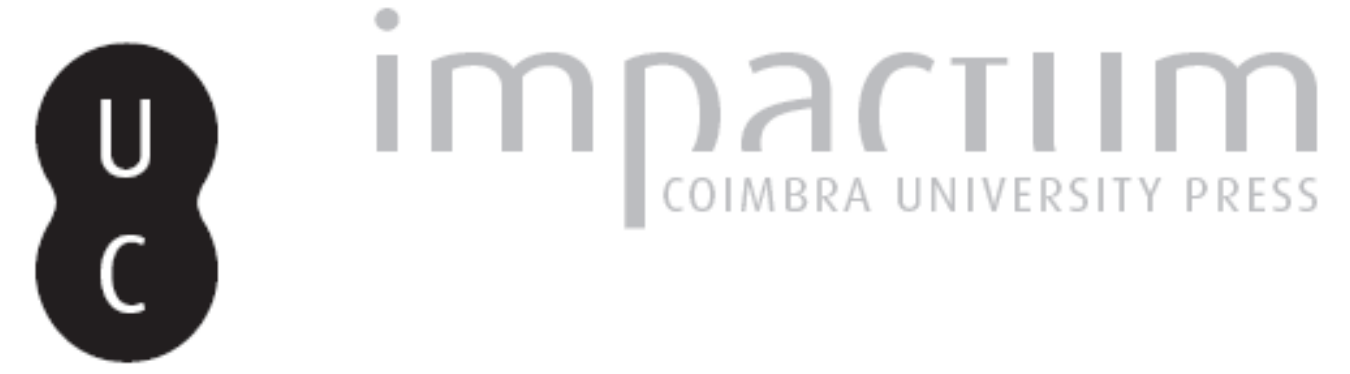

\title{
[Recensao a] KOTOWICZ, Zbigniew - Psychosurgery. The birth of a new scientific paradigm. Egas Moniz and the presente day
}

\author{
Autor(es): $\quad$ Correia, Manuel
}

Publicado por: Imprensa da Universidade de Coimbra

URL persistente:

URI:http://hdl.handle.net/10316.2/36788

DOI:

DOI:http://dx.doi.org/10.14195/1647-8622_12_25

Accessed : $\quad$ 26-Apr-2023 11:08:39

A navegação consulta e descarregamento dos títulos inseridos nas Bibliotecas Digitais UC Digitalis, UC Pombalina e UC Impactum, pressupõem a aceitação plena e sem reservas dos Termos e Condições de Uso destas Bibliotecas Digitais, disponíveis em https://digitalis.uc.pt/pt-pt/termos.

Conforme exposto nos referidos Termos e Condições de Uso, o descarregamento de títulos de acesso restrito requer uma licença válida de autorização devendo o utilizador aceder ao(s) documento(s) a partir de um endereço de IP da instituição detentora da supramencionada licença.

Ao utilizador é apenas permitido o descarregamento para uso pessoal, pelo que o emprego do(s) título(s) descarregado(s) para outro fim, designadamente comercial, carece de autorização do respetivo autor ou editor da obra.

Na medida em que todas as obras da UC Digitalis se encontram protegidas pelo Código do Direito de Autor e Direitos Conexos e demais legislação aplicável, toda a cópia, parcial ou total, deste documento, nos casos em que é legalmente admitida, deverá conter ou fazer-se acompanhar por este aviso.

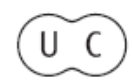


histórias da saúde

ESTUD OSD O SÉCULO

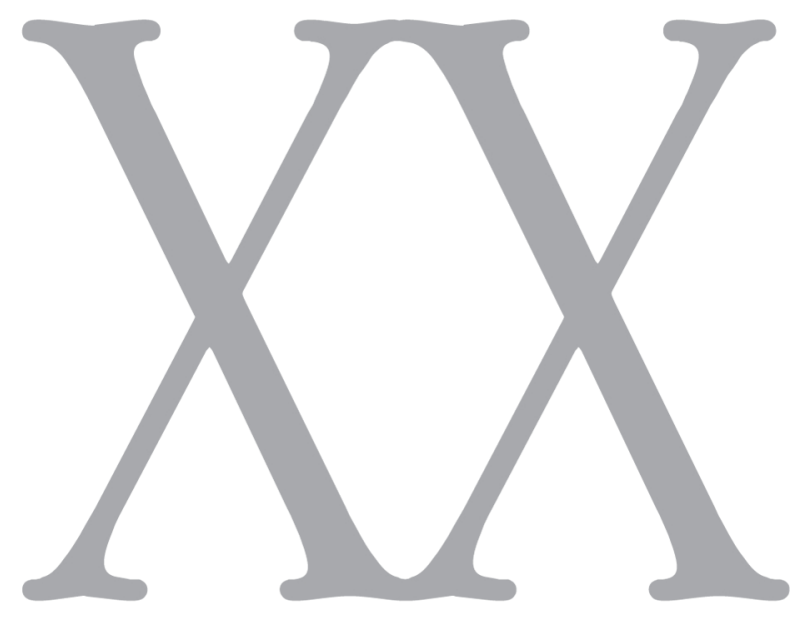

número 12 • 2012

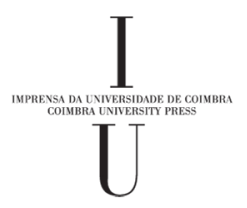


à relevância e actualidade dos assuntos investigados, bem como à abordagem pluridisciplinar ao tema da integração de Portugal na União Europeia, o número 10 da Colecção Estudos sobre a Europa constitui um volume de elevado interesse para um público bastante diverso. Com o mesmo rigor e amplo escopo dos anteriores números, o actual volume apresenta-se como uma boa base para reflexóes mais aprofundadas sobre processos fulcrais da nossa adesão às Comunidades Europeia.

Isabel Maria Freitas Valente Doutoranda FCT/FLUC Investigadora Colaboradora do CEIS20 Membro Team Europe

KOTOWICZ, Zbigniew - Psychosurgery. The birth of a new scientific paradigm. Egas Moniz and the presente day. Centre for Philosophy of Science of the University of Lisbon, 2012. 216 p. ISBN 978-9898247-47-6.

Zbigniew Kotowicz, atualmente investigador do Centro de Filosofia da Ciência da Universidade de Lisboa, deu à estampa recentemente o livro intitulado "Psychosurgery. The birth of a new scientific paradigm. Egas Moniz and the presente day".

O autor consagrou ao tema uma série de artigos acerca da Psicocirurgia e apresenta-nos agora uma síntese a que acrescenta algumas teses fruto de uma reflexão acerca da emergência da psicocirurgia, considerados alguns traços biográficos, o contexto internacional e a História da Psiquiatria.

Zbigniew Kotowicz passa em revista a documentação mais significativa relacionada com a génese da Psicocirurgia, chamando a atenção para a proposição que está na base do desenvolvimento do que considera uma espécie de programa de investigação: a doença mental é uma doença do cérebro. A referência que o autor faz aos "programas de investigação" no sentido que lhe atribuiu Imre Lakatos traz automaticamente para primeiro plano uma das bandeiras kantianas do filósofo húngaro, ao sustentar que a filosofia $d a$ ciência sem a história da ciência é vazia; e a história da ciência sem a filosofia $d a$ ciência é cega ${ }^{l}$.

$\mathrm{O}$ autor discute as tendências que se formaram desde meados do Século XIX para artilhar esse programa de investigaçáo com metodologias apropriadas, levando a uma espécie de fusão da psiquiatria com a neurologia, desembocando na hibridez da neuropsiquiatria cuja inconsistência epistemológica é extensivamente discutida.

Zbigniew Kotowicz não aceita algumas das ideias mais simplistas colhidas facilmente na literatura acerca da natureza neurocirúrgica da psicocirurgia. Para ele a psicocirurgia não é uma extensão da neurocirurgia, mas opostamente uma clara violação das regras epistemológicas que aliam a neurologia e a neurocirurgia.

E este é talvez um dos territórios mais estimulantes da discussão que trava. Para o autor, a linha divisória entre a neurologia (que se poderia estender hoje às neurociências) e a psiquiatria, apesar de relativizada por muitos, permanece justificada pela diferença fundamental entre os respetivos objetos.

A articulação entre história da psiquiatria, história da psicocirurgia e a biografia de Egas Moniz acrescenta algumas

${ }^{1}$ LAKATOS, Imre - História da Ciência e suas reconstruçōes racionais. 1a Edição. Lisboa: Ediçōes 70, 1998, 176p. ISBN 972-44-0958-9. p. 21. 
anotaçóes pertinentes acerca da lógica individual dos procedimentos que puseram Moniz na senda da psicocirurgia, as suas principais propostas, o silêncio embaraçoso a que deu azo e uma certa caricatura intelectual e científica a que o autor se opóe determinadamente, denotando um conhecimento aprofundado da história de vida de Egas Moniz e dos seus próximos, diferenciando-o de Burckhardt, o (neuro) psiquiatra suíço que é recorrentemente alinhado como precedente na história da psicocirurgia. Zbigniew Kotowicz salienta os fatores que ajudam a compreender as razóes pelas quais a experiência de Burckhardt foi criticada e execrada, enquanto a iniciativa de Egas Moniz, apesar da incerteza dos resultados, da intensa controvérsia que envolveu, com altos e baixos, permaneceu na prática clínica e esteve mesmo na base da atribuição do Prémio Nobel da Fisiologia ou Medicina que Egas Moniz recebeu em 1949, ex aequo com o neurofisiólogo suíço Walter Rudolph Hess.

O livro Psychosurgery. The birth of a new scientific paradigm. Egas Moniz and the presente day contém ainda uma série de reflexôes estimulantes acerca dos limitaçóes das neurociências para descreverem e compreenderem satisfatoriamente o psiquismo, compulsando igualmente alguns dos dilemas científicos e éticos que o autor correlaciona com a temática: neurociências/psiquiatria; investigação científica/atividade clínica.

Um dos capítulos é dedicado ao caso célebre de Phineas Gage que Egas Moniz nunca referiu mas se tornou clássico na literatura corrente. $\mathrm{O}$ autor traça a sua própria análise do caso polemizando com António Damásio, entre outros, acerca da estreiteza e enviesamento de estudos anteriores.

O conjunto de publicaçóes de que
Zbigniew Kotowicz é autor abarca diferentes áreas temáticas de que são exemplo os seus livros sobre Laing ${ }^{2}$ e Fernando Pessoa ${ }^{3}$.

Os seus pontos de vista acerca de Egas Moniz e da Psicocirurgia constituem uma abordagem original em muitos aspetos. A tese de que Egas Moniz, ao imaginar as ideias obsessivas como curto-circuitos na rede neuronal interrompendo cirurgicamente "certas" conexôes, criou um novo paradigma, merece atenção; as aparentes incoerências de um neurologista e professor de neurologia que acobertava no seu ideário a psicanálise e o hipnotismo juntamente com a convicção de que era nos fluxos energéticos e nas sinapses que residiam as bases fundamentais do psiquismo normal e patológico, requer evidentemente uma discussáo à altura do excelente texto que o autor nos trouxe.

Uma tradução para língua portuguesa seria certamente bem-vinda.

Manuel Correia Investigador Integrado do CEIS20

${ }^{2}$ KOTOWICZ, Zbigniew - R. D. Laing and the paths of anti-psychiatry. $1^{\text {st }}$ Edition. London: Routledge, 1997. 132 p. ISBN 0-415-11610-4.

${ }^{3}$ KOTOWICZ, Zbigniew - Fernando Pessoa. Voices of a nomadic soul. $2^{\text {nd }}$ Edition. London: The Menard Press. 116p. ISBN 978-1-905700-31-8. 